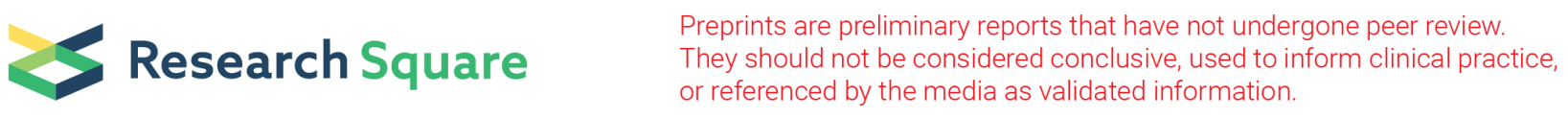

\title{
Tonic down-rolling and eccentric down-positioning of eyes under general anaesthesia without non-depolarising muscle relaxant
}

\section{Shweta Chaurasia ( $\nabla$ shweta84omns@yahoo.com )}

Post Graduate Institute of Medical Education and Research, Chandigarh, India

Shiv Lal Soni

Post Graduate Institute of Medical Education and Research, Chandigarh, India

Venkata Ganesh

Post Graduate Institute of Medical Education and Research, Chandigarh, India

\section{Jagat Ram}

Post Graduate Institute of Medical Education and Research, Chandigarh, India

\section{Jaspreet Sukhija}

Post Graduate Institute of Medical Education and Research, Chandigarh, India

\section{Swati}

Sanjay Gandhi Memorial Hospital, New Delhi

\section{Aastha Takkar}

Post Graduate Institute of Medical Education and Research, Chandigarh, India

\section{Research Article}

Keywords: Down-rolling of eyes, eccentric eye positioning, down-gaze, minimal aleolar concentration, bispectral index, general anaesthesia, sevoflurane, non-depolarising muscle relaxants, supra-glottic

Posted Date: March 7th, 2022

DOI: https://doi.org/10.21203/rs.3.rs-354044/v3

License: (c) (i) This work is licensed under a Creative Commons Attribution 4.0 International License. Read Full License 


\section{Abstract}

Purpose: To describe and analyze the relationship between the downward eccentric eye movement/positioning encountered in patients undergoing ophthalmic surgeries under general anesthesia (GA) with fluctuation in the depth of anesthesia (DOA)

Design: observational case-series

Methods. Patients undergoing ophthalmic surgeries under GA without non-depolarizing muscle relaxant (NDMR) between January2018-August2021 who witnessed a sudden tonic downward movement of eyes were included. DOA at the time of eccentric movement were noted in terms of MAC (minimum alveolar concentration) with/without BIS (bispectral index).

Results. A total of 12/249 patients (14 events) were enrolled in this study with a median (IQR) age of 1.05years (0.8-1.57). All cases were performed with sevoflurane as an inducing agent. Downward movement /down-positioning of eyes was seen before the start of surgery in 7, during surgery in 6 , and end of surgery in 1 case. It was preceded by an eccentric upward drift of eyes in 6 cases. A strong negative correlation was seen between DOA and eccentric eye position $(r=-0.77, p=0.000)$. Median (IQR) MAC and eye position/score in 14 events at the time of eccentric down-rolling was 1.55(1.40-1.83) and $-3(-4$ to -2.0$)$ respectively while median (IQR) MAC at the time of centralized position was 1.25(1.18-1.40). BIS values were inconclusive in 2 cases but corroborated elevated and downward eye positions with lighter and deeper DOA respectively in 2 cases.

Conclusions. Tonic-down-rolling/downward eccentric positioning of eyes is not an uncommon entity in children under GA without NDMR, and fluctuations in DOA should be avoided to circumvent inadvertent complications during ocular surgery.

\section{Introduction}

Anaesthetized patients go through Guedel's ${ }^{1}$ stages of general anesthesia (GA). Stage 3 (surgical anesthesia) is made up of four planes. As the DOA (depth of anesthesia) increases, the extraocular muscles become flaccid and the eyeball movement ceases. But eye movements on the operating table are not uncommon. ${ }^{2,3,4}$ Investigators found that during ocular surgery under $\mathrm{GA}, 18 \%$ of patients had eccentric eye movements. ${ }^{3}$ These days anesthetist cannot observe the Guedel stages as plane 3 is reached in seconds with the newer volatile anesthetic drugs, such as sevoflurane, which has become common for inhalational induction in children. The newer drugs' rapid manipulation of anesthetic planes allows patients to move quickly between deeper and superficial planes. This fluctuation in anesthetic depth can happen even if the MAC multiple (Minimum Alveolar Concentration) is kept between 0.8 and $1.2 \mathrm{or}$, in most situations, more than one MAC multiple for recall prevention. For an ophthalmologist, eccentric eye movements can pose a surgical challenge due to constriction of the field of surgery and sudden jerk which can cause inadvertent iatrogenic complications at different steps of surgical procedures like cataracts, squints, etc.

Slightly divergent and elevated eye positions during GA is a known finding. 2,5,6,7 But only a few studies have described fixed vertically deviated eye positions during ocular surgery under GA and discussed its definite relationship with anaesthetic depth. ${ }^{2,3,4}$ According to a quantitative study, lighter planes of anesthesia without non-depolarizing muscle relaxants (NDMR) correlate with higher eye position, ${ }^{4,6,7}$ which has been explained on the basis of natural Bell's phenomenon. Only a few authors have mentioned deeper levels of anesthesia with the down positioning of eyes. ${ }^{2,4}$ To the best of our knowledge, there is no literature on detailed documentation of abrupt eccentric downward movement/down-positioning of eyes, their relationship with variability in anesthetic depth and co-occurrence of eccentricup-positioning.

So, we here aimed to investigate and correlate the tonic downward movement of the eyes and their eccentric positioning in down gaze encountered during ocular surgery under GA in the absence of NDMR with the DOA. Also, we wanted to evaluate timing of tonic downward eye movement and its relationship with upward eye movement. This retrospective study aims to raise awareness of this common ocular finding in children under GA that has important consequences in ophthalmic surgery. Using our study's findings, we hope to evaluate the literature and gain insight into the intricacy of neuronal processes in subcortical regions mediating tonic eye movements under GA.

\section{Materials And Methods}


The study adhered to the tenets of the Declaration of Helsinki and the study was reviewed and approved by our Institutional Ethics committee of the Postgraduate Institute of Medical Education and Research, Chandigarh, India. Operative records of 249 paediatric patients who underwent surgeries (operated by single surgeon SC) under GA with supraglottic airway device without NDMR between January 2018 and August 2021 were retrospectively reviewed and cases in which vertically downward movement was witnessed with or without accompanying upward movement under direct observation during surgery were included in our study. Exclusion criteria were eccentric upward movement alone (without accompanying downward movement or down-positioning), the unavailability of intra-operative details of eye movements, unrecorded values of anaesthetic details at the time of eye movements. Written informed consent was obtained from all patients' parents or guardians regarding their study participation and publication of any identifying image.

"Eccentric eye movement" is defined as the off-axis vertical movement of the eye from its central position in a quickrolling/drifting fashion. "Eccentric position" is defined as off-axis vertically deviated positioning of the eye from its central position after the vertical eye movement. This eccentricity is either described as upward or downward depending on the movement/position of the eye towards the upper fornix or lower fornix respectively "In our study, the term "drift" and "rolling" have been interchangeably used for the upward and downward movements as these movements were smooth and slow similar to the drifts seen in dissociated vertical deviation or slow rolling eye movements seen during sleep onset/Bells phenomenon." Also, both terms describe sweeping eye movements with marginally slow speed (encountered in our study) and differentiates them from rapid eye movements/saccades of the awake state. An electronic search was performed using keywords: eye movement, general anaesthesia, eccentric eye position, anaesthetic depth, sleep, and anaesthesia. The search of published literature for the review was made via PubMed, Med line, Google Scholar, and Ovid along with checking for crossreferences.

The airway was maintained with a supraglottic airway device using sevoflurane, oxygen, and nitrous oxide (50:50) without a muscle relaxant. A BIS (bispectral index) monitor (Aspect-2000; Aspect Medical Systems, Newton, MA, USA) and a BIS paediatric sensor (Aspect Medical Systems) were used to monitor DOA. Anaesthetic details including the drug used as an induction agent, its concentration, and corresponding values of $\mathrm{MAC}^{8}$ of the anaesthetic agent at the time of onset and sequence of events prior and following downward eye movements in different cases were noted. MAC is defined as the concentration of inhaled anaesthetic within alveoli at which $50 \%$ of people show immobility in response to any nociceptive stimulus. MAC was employed as a reproducible metric to determine the adequacy of anaesthetic dosing based on the assessment of a motor response to a surgical stimulus. Any oculo-cardiac reflex if present and any change in heart rate were noted. Types and duration of surgery were noted. The BIS values if used and recorded were noted. BIS monitoring system uses processed electroencephalography (EEG) parameters for measuring the hypnotic effect of anaesthetic drugs on the central nervous system. ${ }^{9-12}$ The BIS value of 65 to 85 is recommended for sedation, and a value of 40 to 65 for general anaesthesia. ${ }^{9}$

Records of eccentric down-positioning of eyes were evaluated and the inferior positions of eyes (towards inferior fornix) in relation to the medial canthus and superior limbus/superior half of cornea was scored on an ordinal scale from -4 to 0 (Figure1).

$-4=$ line joining medial and lateral canthi passes above the superior limbus

$-3=$ line joining medial and lateral canthi passes via superior limbus

$-2=$ line joining medial and lateral canthi passes between superior limbus to superior one-fourth cornea

$-1=$ line joining medial and lateral canthi passes between superior half to one-fourth cornea

$0=$ pupil position aligning medial canthus

Similarly, positive values $(0$ to +4$)$ reflected superior positions of eyes (towards superior fornix) in relation to the medial canthus and inferior limbus or inferior half of the cornea. 
Statistical analysis was done by IBM SPSS software V 22.0. Median (Interquartile range) was calculated for all skewed discrete, continuous ratio data. All eye positions including up, central and down eye positions with various scores correlated were with DOA (in terms of MAC) via spearman rank correlation, and $p<0.05$ was considered clinically significant.

\section{Results}

A total of 48 patients were identified to have up-rolling/down-rolling eccentric eye movements or upward or downward eccentric eye positions among a total of 249 children who underwent ophthalmic surgery (from the start to end of surgery) under GA without muscle relaxants surveyed over 59 weeks between January 2018 and August 2021. Among them, only 14 patients were found to have the downward eccentric position of eyes with or without upward eccentric eye position. Rest patients witnessed upward movement alone during lighter planes of anesthesia. As intra-operative anaesthetic details were not available in 2 patients, we populated the data for 12 of these patients. Among 12 patients, 2 patients re-encountered tonic down-rolling during subsequent surgeries. All patients underwent surgeries under GA without NDMR except 1 patient (patient no 7; Table1) who had recurrence under GA with NDMR but was included in the analysis as eccentric movement was encountered when the effect of NDMR waned off (patient no 6; Table 1). Hence, 14 down-rolling events were included in the study for final analysis. Median (IQR) age was 1.05years (0.89-1.58). There were 7 male and 5 female patients. Heart rate (HR)

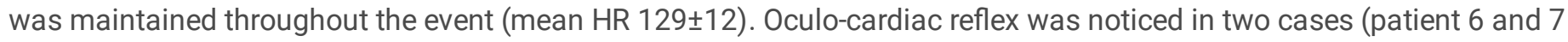
during re-surgeries out of which one required glycopyrrolate for remission; Table1) which preceded the downward event. Among 12 cases, 3 were pediatric cataracts who underwent cataract surgery, 7 were infantile esotropia who received botulinum injection in both eyes of medial rectus, 1 was pseudophakia with posterior capsule opacification (PCO) who underwent capsulotomy, 1 was infantile exotropia who underwent 2 muscle (bilateral lateral rectus) surgery and 1 was infantile esotropia with inferior oblique over action who underwent 4-muscle (bilateral medial rectus and inferior oblique) surgery (Table1).

\section{Relationship of down-rolling with anesthetic agent used}

All cases were performed under GA using sevoflurane in 50\% oxygen/nitrous-oxide mixture as an inducing agent with fentanyl 0.5-2mg / $\mathrm{kg}$ 13/14 episodes were witnessed under GA with sevoflurane without NDMR and 1/14 patients witnessed downrolling during switching of sevoflurane to isoflurane during termination of 4 muscle squint surgery (40 minutes duration) when effect of NDMR (atracurium $0.5 \mathrm{mg} / \mathrm{kg}$ whose effect last 30-40 minutes) waned off.

\section{Timing of downward drift and its relationship with upward drift}

Down-rolling/positioning of eyes was seen either (a) with upward drift or (b) without upward drift

(a) In 6 cases, downward drift during surgery was preceded by upward drift (Table1). Eyes of 2 patients (patient 1\& 5; Table1) were found up-rolled before the start of surgery after cleaning, draping, and putting eye speculum (Figure 1; e-video1) and 4 patients encountered up-rolling following start of surgery with/without noxious stimuli (e.g., traction, during conjunctival incision) (patient2,3,4,6). This upward drift was seen when the DOA was on the borderline lighter side in all cases. Documented median (IQR) MAC in 5 cases at the time of upward drift was 1 (0.95-1.1). Among these 5 patients, BIS was documented in two cases (77\&55; patient $5 \& 6$ respectively, Table1). When anesthetists were informed of the up-rolling of eyes, increase in sevoflurane concentration was (increase in DOA) was used as a measure to resolve the problem in all cases. Within a few minutes of increasing sevoflurane concentration, the eye returned to its primary position but as the procedure was about to be

re-started eyes overshoot in down gaze at the same time (Figure 1, e-video 1, e-video2). Eyes also down-rolled during important steps in few patients e.g., just before re-introducing phacoemulsification probe, injection of Botulinum toxin in medial rectus 
etc. The downward movement caused the eye to acquire an eccentric eye position in down gaze, thereby interrupting the surgery.

(b) Downward eye eccentric position of eyes without upward drift was seen in 7 patients (total 8 events; Table1). 5 events of downward eccentric down-positioning were encountered before the start of surgery after cleaning and draping when eyes were found eccentrically down-positioned (Figure2a, c; e-video 3). 2 events occurred after the start of surgery during intermittent withdrawal of traction in eye (at the same MAC, when eyes were central and surgery was started; Figure2b). And one event of downward rolling was witnessed in a patient at the end of surgery during reversal of GA (switch from sevoflurane to isoflurane when anesthetic concentration inside lungs became momentarily high) after the effect of NDMR waned off (eFigure4).

When the surgeons tried to manually rotate the eyes to the central position, difficulty was felt as the tonic downward force was experienced by the surgeons in all cases. The surgical procedure was abandoned for few minutes as in presence of an eccentric eye position, the continuation of the surgical procedure became unexpectedly difficult. The anesthetists were informed about the eccentric downward movement and its eccentric down-positioning to which the anesthetist was not able to comment on the relationship between the DOA and specific downward movement of the eye, beyond what was being informed by the MAC value which was adequate for the patient. This was quite intriguing as traditionally upward eye movement has been associated with a lighter plane of anesthesia.

\section{Correlation between DOA and eye position}

Adequate DOA was noted in all 12 cases/14 episodes when eyes were found in extreme down-drifted positions. The median (IQR) eye score at the time of down-drift was -3(-4 to -3). All eyes were slightly adducted during eccentric positioning in down gaze (opposite of upward and outward positioning in up-gaze). Documented median (IQR) MAC in 14 episodes at the time of eccentric movement in down gaze was 1.55 (1.40-1.83). Strong negative correlation between MAC (DOA) and various eye position (scores -4 to +4 ) was found $(r=-0.77 ; p=0.000)$. BIS was measured during 5 events and recorded BIS during downrolling events were $62,30,66,34$ and 36 in patient 5,6 (1st), $6\left(2^{\text {nd }}\right), 9 \& 12$ respectively; Table1\}. Lower BIS values during down-rolling and high BIS during centralized eye position were seen in 3 patients \{patient $\left.6\left(2^{\text {nd }}\right), 9,12\right\}$. BIS was adequate throughout procedure and did not differ much during down-rolling or centralized position of eye in other 2 patients \{patient 5 and $\left.6\left(2^{\text {nd }}\right)\right\}$.

\section{Duration of downward eye positioning and return of down-drifted to the central position}

When down-positioning of eyes was encountered, anesthetists usually decreased the DOA slightly, on a trial basis towards the recommended lower limit for amnesia, by decreasing the volatile agent. Eccentric downward eye position was maintained till anesthetic depth was slightly lightened \{as indicated by decreased median (IQR) MAC was 1.25 (1.18-1.4)\} when eyes returned to their resting position. Median (IQR) duration of downward eye positioning was 60 seconds (44-94)\} which related to how fast MAC was changed. This might have been influenced by varying rates at which the individual anesthetist adjusted DOA. Eccentric down-positioning of eyes partially interrupted the ongoing surgical procedure till the DOA was balanced to make the eyes return to its resting position. Tonic downward movement was quick (spanning few seconds) but the return was slow and smooth. Further decrease in DOA slowly drifted upward at the time when surgery was terminated. All the movements were smooth throughout. No complications were encountered as fortunately during the movements no instruments were close to important structures of the eye.

\section{Relationship of repeated anesthetic exposure on the incidence of downdrift}

Among 12 patients, 7 patients (patient1,2,5,7; Table1) underwent repeat surgeries under GA without NDMR (patient1,4,7,8,9,10,12) and 1 patient underwent surgery under NDMR (patient 6) but the repeat downward drift was seen as 
two episodes in 2 patients. (Patient 6\&7). Downward drift was symmetrical in both eyes except case7, in which downward scoring of right was more than left eye (Figure 3a). Pre-operative records of that patient (case7) revealed left eye dissociated vertical deviation (Figure 3b).

\section{Relationship with change in pupil size}

No change in pupil size was noted throughout. The media pupil size was $1.75 \mathrm{~mm}$ in 8 squint patients at the time of the start of the procedure. Proparacaine was given to all patients before the start of the procedure. In the rest 4 patients (3 pediatric cataracts and 1 pseudophakia with posterior capsular opacification), change in pupil size could not be estimated as pupils were pharmacologically dilated for the surgical procedure (Table1).

\section{Discussion}

Adequately deep plane of anesthesia was found at the time of eccentric fixation of eyes in down gaze on all occasions in our study. This was demonstrated by the higher value of MAC in all cases. Eye score $(-4$ to +4$)$ showed a significant negative correlation with DOA, thereby confirming elevated eye position with lighter anesthesia and downward eye position with a deeper level of anesthesia. ${ }^{4,7}$ In his study under different depths of general anesthesia, Power et al ${ }^{13}$ observed final eye position in downward direction in few patients but their number, DOA, and down-scoring of eye position were never described. In his study of 32 patients, Kook et $\mathrm{al}^{2}$ scored the vertical position of each eye on an ordinal scale from -2 to +6 , according to its height in relation to the medial canthus, and studied the relationship between fixed eccentric eye elevation and DOA during surgery in 32 children. He encountered elevation of the eyes in $83 \%$, and downward position of eyes was in $2 \%$ ( 1 child) with BIS values less than $35 .{ }^{2}$ BIS was performed only in $5 / 14$ surgeries in our series. Though values of BIS in infants and young children do not indicate a similar concentration of sevoflurane like adults, ${ }^{14}$ lower values of BIS generally indicate deeper level of anesthesia. Lower values of BIS corroborated deep anesthetic level in 3 events, but BIS values did not corroborate the DOA during the other 2 events. (Table1) which could be understood with the fact that BIS values are not validated in small children and hence may not be always reliable.

This tonic downward movement was seen in pediatric cases under sevoflurane GA in absence of muscle relaxant (or when effect of NDMR waned off in one case) when attempts were made to rapidly deepen/optimize the plane of anesthesia (on surgeon's request to centralize eye position from eccentric positioning in up-gaze) or before the start of surgery when eyes were opened after cleaning and draping procedure following handing over the anesthetized child to ophthalmic surgeon by the anesthetist when or after the start of surgery when traction was relaxed in-between. Power et $\mathrm{al}^{13}$ while studying the DOA in young adults via sevoflurane induction compared eye signs with EEG polysomnography and showed that, the deepest level of sleep was reached on an average 3 minutes before the onset of eccentric ocular positioning thereby suggesting that eccentric eye movements may occur even when a patient appears satisfactorily anaesthetized. This also points towards understandable lag between anesthetic depth reached at the level of lungs and its effect seen at the level of CNS (eccentric eye positioning). This could be the possibility, as most of our patients experienced downward movement at or before the start of surgery. During induction sevoflurane flow to lungs is generally kept high (MAC is kept high during induction barring the level of apnea) and then slowly decreased to desired level once the child gets anesthetized which is continued even after handling the child to ophthalmic surgeon. Rapid induction might overlap this lag with short duration surgeries when most of the children witnessed downward or upward movement before/at the start of surgery, depending on DOA and child's threshold value. Also, rapid increase in flow of sevoflurane to centralize upward eye-positions (deepen DOA) also explained rapid downward movement following upward movement (patient 1). Few children witnessed downward rolling at the end of surgery at the same MAC, surgery was performed, and the probable reason could be that DOA (although MAC was kept constant) varies with the level of stimulus (like traction on eye) the patient is experiencing. This may be illustrated by the fact that one of our patients experienced downward movement at the end of surgery (during conjunctival suturing) on the same MAC (1.3) eyes were central and was being operated upon. 
In 1848 Snow ${ }^{15}$ defined the cessation of voluntary eye movement and a slight inclination of eyes in up-gaze as the point of sufficient anesthetic depth. Rossiter et $\mathrm{al}^{3}$ reported its substantial increased incidence without the use of muscle relaxants. Higher incidence of up-gaze eccentric movement (34.4\%) in Kook's study ${ }^{2}$ was due to an extended duration of the measurement period, including the time of emergence from anesthesia as upward eye positioning is more commonly seen at the end of surgery when anesthesia is lightened. In our case series also upward drifting of the eyeball was seen under lighter planes of anesthesia during eye manipulation during surgery as demonstrated by lower MAC values (median 1.0) in 5 patients in which upward drift was seen during surgery. The high BIS value (55) recorded in case1 corroborated the findings of the prior studies. ${ }^{4,7}$

Inhalational agents are known to cause a dose-dependent suppression of reflexes and movements. ${ }^{5}$ Complete lack of electrical discharge in the extraocular muscles occurs only during deep sleep or deep anesthesia. ${ }^{5}$ But the increased DOA is not always effective in reducing eye movements. ${ }^{13,16}$ Moreover, different anaesthetic agents may have different effects on eye movements. ${ }^{17}$ Presence of electrical activity in one of the extraocular muscles occurs over its opposing muscle in the lighter plane of anesthesia, and probable causation has been discussed in the literature by many researchers. Rossiter et al reasoned intense and sustained contraction of superior rectus (SR) behind the eccentric upward eye position. ${ }^{3}$ Harrad and Stoddart ${ }^{18}$ suggested that Bell's phenomenon, a natural protective reflex, in which the globe rolls up in response to any noxious stimuli in the form of pressure on the globe or any manipulation of the eyeball may explain this upward eccentric eye position. ${ }^{19,20}$ This occurs both in the awake state and with lighter planes of anaesthesia (though the patient is not awake) which may explain the entity. The exact neural mechanism is unknown but involves brainstem pathways between the seventh cranial nerve nucleus in the pons and the third cranial nerve nuclear complex in the rostral midbrain. Hiraoka et $\mathrm{al}^{21}$ have suggested that the mesencephalic reticular nucleus may play an important role in integrating these two patterns of movement (bilateral lid closure and upward movement of both eyes). Bell's reflex is also extinguished with deep planes of anaesthesia, such that the eye remains in the neutral gaze. ${ }^{18,22}$ And this upward drift in cases 2,3 , and 4 prompted the anesthetist to increase the DOA to make the eyes return from the upward position following which down-rolling was encountered.

In our study, down-rolling made surgeons abandon the procedure till the time it lasted. Similarly, it appeared to have resulted from a tonic contraction of the inferior rectus of both eyes, as it was difficult to manually rotate the eyes and carry the procedure. All cases had symmetric down-rolling (Figure4) except case 6 in which asymmetry was evident (Figure3). Though we could not understand the exact reason of asymmetry, but we suspected asymmetric dissociated vertical deviation in the child to alter the eye position.

\section{Probable pathophysiology behind downward drift}

The pathophysiology of down-rolling under GA is unknown. We tried to hypothesize based on the shared neurochemical and behavioral features of sleep and general anaesthesia. ${ }^{23,24,25}$ Various anesthetics have been demonstrated to alter brain systems involved in sleep-wake control. ${ }^{24,25,26,27}$ Many medicines produce general anesthesia that is very comparable to NREM sleep ${ }^{28}$, including a breakdown in efficient cortical communication ${ }^{29,30}$ and inactivation of the thalamus and midbrain reticular formation along with loss of awareness. ${ }^{31,32}$ Anaesthetized patients' brains may be trapped into an NREM-like state, preventing access to REM sleep and waking. ${ }^{31,33}$ In a wakeful state, the mesencephalic reticular development is critical in creating a vertical saccade. ${ }^{34}$ REM sleep activates cholinergic neurons in the reticular formation. ${ }^{35}$ The similar velocityamplitude correlations of rapid eye movements during REM sleep and spontaneous saccades in the dark when awake, suggest a shared neural circuit. ${ }^{36}$ Since eye movements changed with MAC, we hypothesize that a sudden increase in anesthetic concentration (which might have been potentiated with use of sevoflurane during induction for deepening or maintenance of 
DOA during surgery) caused temporary irritative effects in the central nervous system, causing temporary switching ${ }^{37}$ of nonREM to REM sleep-like state or isolated REM sleep-like traits being expressed during non-REM sleep-like state ${ }^{38}$ with activation of the mesencephalic reticular formation and neurons.

The irritative effect of increased anesthetic concentration can be many-fold, although prospective studies are required to evaluate these theories.

1. An increase in sevoflurane concentration (higher MAC) and differential sensitivity of cortical and subcortical areas to sevoflurane concentrations. ${ }^{39}$ In adults, Mourisse and colleagues ${ }^{40}$ found that the blink reflex (brainstem function) was more susceptible to sevoflurane than BIS (forebrain function). The interstitial nucleus of Cajal, the mesencephalic reticular formation, and the posterior commissure are all located at the meso-diencephalic junction. ${ }^{41}$ Forced downward gaze is prominent in this area's lesions, indicating a vertical gaze plane imbalance. ${ }^{42}$ In our cases, down gaze neurons in the midbrain were possibly selectively irritated by sevoflurane. ${ }^{43,44}$ Prepubertal children's lesser sensitivity to sevoflurane for specific subcortical areas (i.e. mesencephalic control) than older subjects may explain its prevalence only in select children. ${ }^{39}$ Different flow rate of anesthetic agent used, different time taken and different DOA achieved during intubation and as well as different DOA (MAC value) on which the patient is stabilized before handing them over to the ophthalmic surgeon for the procedure, could be factors influencing the non-occurrence of eye movements during repeat exposures in the same patients.

2. Another potential reason could be related to shortened autoregulation and vasodilatory impact of sevoflurane generating transient reduced cerebral blood flow (CBF) and irritative effect which reverses when concentration is decreased. ${ }^{45,46}$ The lower limits of sevoflurane autoregulation are close to young children's basal mean arterial pressure. ${ }^{47}$ The fact that our patients' exhibited eye movements beyond 1.5 MAC supports this hypothesis, as CBF remains unchanged by sevoflurane up to $1.5 \mathrm{MAC}$ value. $^{45,48}$ It is possible that the CBF sensitivity window is quite narrow and specific to each individual. it is likely that the narrow autoregulation limit was violated when the depth went above the child's acceptable limit. The posterior circulation zone supplying the mesencephalic-diencephalic junction, comprises structures critical for vertical sight and vergence, ${ }^{49}$ may be transiently impaired, manifesting eye movements. The concentrations at which these downward movements were seen in our cases necessarily do not lead to cerebral ischaemia in healthy children as thousands of sevoflurane inductions are performed every day in children, and neurologic complications are quite rare. The movement occurred only when the MAC level was below or beyond the narrow limit in sensitive children.

Burst neurons and tonic neurons are the two types of saccade-generating neurons. ${ }^{22}$ Burst neurons produce high-frequency bursts of action potentials right before the eye movement, whereas tonic neurons fire at regular intervals to keep the eye in the new eccentric position. Also, pause neurons are thought to have a tonic inhibitory influence on saccadic eye movements. Because the mesencephalic reticular structure is activated, the eye moves quickly to down gaze. The ensuing tonic neuron firing may have kept the eye in the downward eccentric posture until the anesthetic wore off. The downward movement was slower than a normal saccade, since most anesthetic drugs reduce peak saccadic velocity dose-dependently. ${ }^{17,50}$ Anesthesia reduces peak saccadic velocity due to the absence of a visual target in the superior colliculus, which increases cells activity in the superior colliculus and corresponding motor pathways.

3. A third possibility is that sevoflurane is known to excite the neurons in Locus Coeruleus (LC). ${ }^{51}$ The LC is a pontine nucleus, with the largest group of noradrenergic neurons in the brain, that is responsible for the tonic maintenance of the wakeful state. ${ }^{52,53}$ This nucleus has very widespread projections to cortical, subcortical regions and to the spinal cord. ${ }^{54}$ In addition, it also projects to the oculomotor nucleus which has been shown to have a high density of a1-adrenoceptors. ${ }^{55,56} \mathrm{It}$ is plausible that sevoflurane, at higher concentrations, induces the activation of the LC leading to the tonic contraction of the muscles innervated by the oculomotor nerve. As the LC is also involved in maintaining the wakeful state, once the DOA is on the lighter side it is possible that the same scenario of LC activation repeats itself. LC activity, through effects on a2-adrenoceptors in the Edinger-Westphal Nucleus, ${ }^{57,58}$ can inhibit pupillary constriction by attenuating the light reflex. This might be the reason why 
we noticed ocular movement without any pupillary change. The interindividual differences in the specificity of these projections, in addition to the fact that MAC per se has been defined for producing immobility to surgical stimulus in $50 \%$ of the population, ${ }^{59}$ may explain why these ocular movements are not noticed in every case.

The limitations of our study are a small sample size and no BIS or EEG monitoring in all participants. The limited sample size limits generalization of reported median MAC values and the usefulness of the association between DOA (MAC value) and eyepositioning score. In addition, because all observations were made after the induction procedure was completed, and the anesthetic depth was stabilized to the desired level, the incidence of downward eye positions may have been underestimated.

This article intends to educate ophthalmologists and anesthetists about this unexpected eye movement during general anesthesia. This entity is important in short ocular procedures or surgeries under GA, especially without NDMR. Our case study demonstrates the importance of keeping a stable DOA. In the event eye movement occurs, the anesthesia team should be contacted immediately, and the surgery should be restarted after the eye movements have stopped, and the eyes have returned to their normal position. Relaxants may be used for novices in ocular procedures involving critical steps like cataracts and squint. Also, more research is needed on the link between eccentric downward movement, eccentric upward movement, and level of anesthesia (using BIS and MAC values) and electrical activity of brain (Electro-encephalogram). Aside from electrooculogram, we need to explore the tonic force in the inferior rectus to understand the pathophysiology of these eye movements, giving clues into ongoing subcortical processes. It will be fascinating to see if an anesthetic drug plays a role in these motions. Further research is required on the entity's link to anesthetic depth and age.

\section{Declarations}

\section{Acknowledgements and Financial Disclosure}

We acknowledge Dr Ashok for his statistical contribution

There are "no financial disclosures" to be made

All authors of this research paper have directly participated in the planning, execution, or analysis of this study and there are no conflicts of interests

\section{References}

1. Guedel AE. Inhalation anaesthesia: a fundamental guide. 1st ed. Macmillan: New York; 1937. p. 63-4.

2. Kook KH, Chung SA, Park S, Kim DH. Use of the Bispectral Index to Predict Eye Position of Children during General Anesthesia. Korean J Ophthalmol 2018 Jun;32(3):234-240.

3. Rossiter JD, Wood M, Lockwood A, Lewis K. Operating conditions for ocular surgery under general anesthesia: an eccentric problem. Eye (Lond) 2006;20:55-8.

4. Seung Ah Chung, Seran Jang, Koung Hoon Kook, Jong Bok Lee; Prediction of eye position during general anesthesia using bispectral index monitoring. Invest. Ophthalmol. Vis. Sci. 2014;55(13):2560.

5. von Noorden GK, Campos EC. Classification of neuromuscular anomalies of the eyes. In: von Noorden GK, Campos EC. Binocular vision and ocular motility: theory and management of strabismus. 6th ed. St. Louis: CV Mosby, 2002.p. 110-28.

6. Apt L, Isenberg S. Eye position of strabismus patients under general anesthesia. Am J Ophthalmol. 1977 Oct;84(4):574-9.

7. Castanera de Molina A, Giner Muñoz ML. Ocular alignment under general anesthesia in congenital esotropia. J Pediatr Ophthalmol Strabismus. 1991 Sep-Oct;28(5):278-82. PMID: 1955965.

8. Eger El, Saidman LJ, Brandstater B. Minimum alveolar anesthetic concentration: a standard of anesthetic potency. Anesthesiology. 1965 Nov-Dec;26(6):756-63.

Page $9 / 14$ 
9. Sebel PS, Lang E, Rampil IJ, et al. A multicenter study of bispectral electroencephalogram analysis for monitoring anesthetic effect. Anesth Analg 1997;84:891-9.

10. McCann ME, Bacsik J, Davidson A, et al. The correlation of bispectral index with end tidal sevoflurane concentration and haemodynamic parameters in pre-schoolers. Paediatr Anaesth 2002;12:519-25.

11. Denman WT, Swanson EL, Rosow D, et al. Pediatric evaluation of the bispectral index (BIS) monitor and correlation of BIS with end-tidal sevoflurane concentration in infants and children. Anesth Analg 2000;90:872-7.

12. Ganesh A, Watcha MF. Bispectral index monitoring in pediatric anesthesia. Curr Opin Anaesthesiol. 2004;17:229-34.

13. Power C, Crowe C, Higgins P, Moriarty DC. Anaesthetic depth at induction: an evaluation using clinical eye signs and EEG polysomnography. Anaesthesia 1998; 53: 736-743.

14. Sciusco A, Standing JF, Sheng Y, Raimondo P, Cinnella G, Dambrosio M. Effect of age on the performance of bispectral and entropy indices during sevoflurane pediatric anesthesia: a pharmacometric study. Paediatr Anaesth. 2017 Apr;27(4):399-408.

15. Snow JD. On the inhalation of the vapour of ether in surgical operations. Br J Anaesth 1953;25:253-67.

16. Laborit G, Angiboust R, Papin JP. A study of eye movement for assessing recovery from anaesthesia. Br J Anaesth. 1977 Aug; 49(8):805-10.

17. Gao F, Marshall RW, Vickers MD. Effect of low concentrations of nitrous oxide and isoflurane on peak velocity of saccadic eye movements. Br J Anaesth. 1991;66 (2):179-184.

18. Harrad RA, Stoddart P. Operating conditions for ocular surgery under general anaesthesia: an eccentric problem. Eye (Lond) 2007;21:256-7.

19. Bell C. On the motions of the eye in illustration of the uses of the muscles and nerves of the orbit. Philos Trans Royal Society of Lond 1823; 113: 166-86.

20. Francis IC, Loughhead JA. Bell's phenomenon. A study of 508 patients. Australian Journal of Ophthalmology 1984; 12: 15-21

21. Hiraoka M. Physiological study of the Bell's phenomenon in human. (Japan). Acta SOC Ophthalmol Japan 1979; 83: 218490.

22. Griffiths AN, Marshall RW, Richens A. Saccadic eye movement analysis as a measure of drug effects on human psychomotor performance. Br J Clin Pharmacol 1984;18 Suppl 1(Suppl 1):73S-82S.

23. Lydic R, Biebuyck JF: Sleep neurobiology: Relevance for mechanistic studies of anaesthesia. Br J Anaesth 1994; 72:5068.

24. Lydic R, Baghdoyan HA: Sleep, anesthesiology, and the neurobiology of arousal state control. Anesthesiology 2005; 103:1268-95.

25. Franks NP: General anaesthesia: From molecular targets to neuronal pathways of sleep and arousal. Nat Rev Neurosci 2008; 9:370-86.

26. Keifer JC, Baghdoyan HA, Lydic R: Pontine cholinergic mechanisms modulate the cortical electroencephalographic spindles of halothane anesthesia. Anesthesiology 1996; 84:945-54.

27. Lu J, Nelson LE, Franks N, Maze M, Chamberlin NL, Saper CB: Role of endogenous sleep-wake and analgesic systems in anesthesia. J Comp Neuro/ 2008; 508:648-62.

28. Karan SB, Perlis M, Ward D. Anesthesia and sleep medicine: An opportunity to be mutually informative? Seminars in Anesthesia, Perioperative Medicine and Pain. 2007;26:42-8.

29. Ferrarelli F, Massimini M, Sarasso S, Casali A, Riedner BA, Angelini G, Tononi G, Pearce RA. Breakdown in cortical effective connectivity during midazolam-induced loss of consciousness. Proc Natl Acad Sci U S A. 2010;107:2681-6.

30. Massimini M, Ferrarelli F, Huber R, Esser SK, Singh H, Tononi G. Breakdown of cortical effective connectivity during sleep. Science. 2005;309:2228-32. 
31. Alkire MT, Haier RJ, Fallon JH. Toward a unified theory of narcosis: Brain imaging evidence for a thalamocortical switch as the neurophysiologic basis of anesthetic-induced unconsciousness. Conscious Cogn. 2000;9:370-86.

32. Fiset P, Paus T, Daloze T, Plourde G, Meuret P, Bonhomme V, Hajj-Ali N, Backman SB, Evans AC. Brain mechanisms of propofol-induced loss of consciousness in humans: A positron emission tomographic study. J Neurosci. 1999;19:550613.

33. Mashour GA, Lipinski WJ, Matlen LB, Walker AJ, Turner AM, Schoen W, Lee U, Poe GR. Isoflurane anesthesia does not satisfy the homeostatic need for rapid eye movement sleep. Anesth Analg. 2010;110:1283-9.

34. King WM, Fuchs AF. Reticular control of vertical saccadic eye movements by mesencephalic burst neurons. J Neurophysiol. 1979 May;42(3):861-76.

35. Brown RE, Basheer R, McKenna JT, Strecker RE, McCarley RW. Control of sleep and wakefulness. Physiol Rev. 2012;92(3):1087-1187.

36. Bahill AT, Clark MR, Stark L (1975) The main sequence, a tool for studying human eye movements. Math Biosci 24:191204.

37. Hayashi Y, Kashiwagi M, Yasuda K, Ando R, Kanuka M, Sakai K, Itohara S. Cells of a common developmental origin regulate REM/non-REM sleep and wakefulness in mice. Science. 2015 Nov 20;350(6263):957-61.

38. George A. Mashour; Rapid Eye Movement Sleep and General Anesthesia. Anesthesiology 2010; 112:1053.

39. Bourgeois E, Sabourdin N, Louvet N, et al. Minimal alveolar concentration of sevoflurane inhibiting the reflex pupillary dilatation after noxious stimulation in children and young adults. British Journal of Anaesthesia 2012;108(4):648-654.

40. Mourisse J, Lerou J, Struys M, Zwarts M, Booij L. Multi-level approach to anaesthetic effects produced by sevoflurane or propofol in humans: 1. BIS and blink reflex. Br J Anaesth 2007;98(6):737-45.

41. Bhidayasiri R, Plant GT, Leigh RJ. A hypothetical scheme for the brainstem control of vertical gaze. Neurology 2000;54:1985-1993.

42. Keane JR. The pretectal syndrome: 206 patients. Neurology. 1990;40:684-690.

43. Sharpe JA: Neural control of ocular motor systems; in Miller NR, Newman NJ (eds): Walsh and Hoyt's Clinical NeuroOphthalmology, 5th edn. (Baltimore, Williams \& Wilkins, 1998) vol 1, pp 1101-1188.

44. Pierrot-Deseilligny C, Chain F, Gray F, Serdaru M, Escourolle R, Lhermitte F: Parinaud's syndrome: Electro-oculographic and anatomical analyses of six vascular cases with deductions about vertical gaze organization in the premotor structures. Brain. 1982;105:667-696.

45. Rhondali O, Mahr A, Simonin-Lansiaux S, De Queiroz M, Rhzioual-Berrada K, Combet S, Cejka JC, Chassard D. Impact of sevoflurane anesthesia on cerebral blood flow in children younger than 2 years. Paediatr Anaesth. 2013 Oct;23(10):94651.

46. Goettel N, Patet C, Rossi A, Burkhart CS, Czosnyka M, Strebel SP, Steiner LA. Monitoring of cerebral blood flow autoregulation in adults undergoing sevoflurane anesthesia: a prospective cohort study of two age groups. J Clin Monit Comput. 2016 Jun;30(3):255-64.

47. Vavilala MS, Lee LA, Lam AM. The lower limit of cerebral autoregulation in children during sevoflurane anesthesia. $J$ Neurosurg Anesthesiol. 2003; 15: 307-312.

48. Fairgrieve R, Rowney DA, Karsli $\mathrm{C}$ et al. The effect of sevoflurane on cerebral blood flow velocity in children. Acta Anaesthesiol Scand. 2003; 47: 1226-1230.

49. Choi KD, Jung DS, Kim JS. Specificity of "peering at the tip of the nose" for a diagnosis of thalamic hemorrhage. Arch Neurol 2004;61:417-422.

50. Yoshizumi J, Marshall RW, Vickers MD. Effects of low concentrations of cyclopropane and halothane on peak velocity of saccadic eye movements. Br J Anaesth. 1991;67 (6):735-740.

51. Yasui Y, Masaki E, Kato F. Sevoflurane directly excites locus coeruleus neurons of rats. Anesthesiology. 2007 Dec;107(6):992-1002. 
52. Dahlstroem A, Fuxe K. Evidence for the existence of monoamine-containing neurons in the central nervous system. I. Demonstration of monoamines in the cell bodies of brain stem neurons. Acta Physiol Scand Suppl. 1964:SUPPL 232:1-55.

53. Jones BE. The role of noradrenergic locus coeruleus neurons and neighboring cholinergic neurons of the pontomesencephalic tegmentum in sleep-wake states. Prog Brain Res. 1991;88:533-43. doi: 10.1016/s00796123(08)63832-7.

54. Loughlin SE, Foote SL, Fallon JH. Locus coeruleus projections to cortex: topography, morphology and collateralization. Brain Res Bull. 1982 Jul-Dec;9(1-6):287-94.

55. Carpenter MB, Periera AB, Guha N. Immunocytochemistry of oculomotor afferents in the squirrel monkey (Saimiri sciureus). J Hirnforsch. 1992;33(2):151-67.

56. Day HE, Campeau S, Watson SJ Jr, Akil H. Distribution of alpha 1a-, alpha 1b-and alpha 1d-adrenergic receptor mRNA in the rat brain and spinal cord. J Chem Neuroanat. 1997 Jul;13(2):115-39.

57. Heal DJ, Prow MR, Butler SA, Buckett WR. Mediation of mydriasis in conscious rats by central postsynaptic alpha 2adrenoceptors. Pharmacol Biochem Behav. 1995 Feb;50(2):219-24.

58. Costa VD, Rudebeck PH. More than Meets the Eye: the Relationship between Pupil Size and Locus Coeruleus Activity. Neuron. 2016 Jan 6;89(1):8-10.

59. Szabo EZ, Luginbuehl I, Bissonnette B. Impact of anesthetic agents on cerebrovascular physiology in children. Pediatr Anesth 2009; 19: 108-118.

\section{Tables}

Table 1. Details of 7 patients who encountered downward drift or had eccentric positioning of eyes in downgaze under general anesthesia without muscle relaxants.

\begin{tabular}{|c|c|c|c|c|c|c|c|c|c|c|}
\hline \multirow[t]{3}{*}{ case } & \multirow[t]{3}{*}{$\begin{array}{l}\text { Age } \\
\text { in } \\
\text { yrs }\end{array}$} & \multirow[t]{3}{*}{ Sex } & \multirow{3}{*}{$\begin{array}{l}\text { Type of Sx/dura of } \\
\text { Sx/No of surgeries } \\
\text { patient } \\
\text { underwent/episode } \\
\text { when down-rolling } \\
\text { occurred }\end{array}$} & \multirow[t]{3}{*}{$\begin{array}{l}\text { Inducing } \\
\text { agent }\end{array}$} & $\begin{array}{l}\text { Any } \\
\text { Preceding } \\
\text { upward } \\
\text { drift/ }\end{array}$ & $\begin{array}{l}\text { Timing of } \\
\text { Downward } \\
\text { drift (B or } \\
\text { D or A) }\end{array}$ & \multirow{3}{*}{$\begin{array}{l}\text { HR during } \\
\text { Downshoot/ } \\
\text { any change } \\
\text { in HR or } \\
\text { OCR }\end{array}$} & \multirow[t]{3}{*}{$\begin{array}{l}\text { Change in } \\
\text { pupil size }\end{array}$} & \multirow[t]{3}{*}{$\begin{array}{l}\text { Duration } \\
\text { of } \\
\text { downshoot }\end{array}$} & \multirow{3}{*}{$\begin{array}{l}\text { Details } \\
\text { when eye } \\
\text { centralized } \\
\\
\text { MAC/ BIS }\end{array}$} \\
\hline & & & & & & & & & & \\
\hline & & & & & MAC/BIS & MAC/BIS & & & & \\
\hline 1 & 1.4 & $\mathrm{M}$ & $\begin{array}{l}\text { Botox } * * / \\
\text { 20mins/3/ } \\
\text { 2nd }\end{array}$ & sevo & $\mathrm{Y} / 1.1 / 55$ & $\mathrm{D} / 1.7 / 30$ & 152/None & $3.5 \mathrm{~mm} /$ none & $\begin{array}{l}1 \mathrm{mins} 40 \\
\mathrm{sec} /-4\end{array}$ & $1.4 / 45$ \\
\hline 2 & 1.5 & $\mathrm{M}$ & $\begin{array}{l}\text { Botox**/20mins/ } \\
2 / 1 \text { st }\end{array}$ & sevo & No & $\mathrm{B} / 1.6 / 34$ & 134/None & $2 \mathrm{~mm} /$ none & $\begin{array}{l}1 \min 10 \\
\mathrm{sec} /-3\end{array}$ & $1.3 / 50$ \\
\hline 3 & 1.8 & $\mathrm{M}$ & $\begin{array}{l}\text { Cataract 15mins/ } \\
1 / 1 \text { st }\end{array}$ & sevo & $\mathrm{Y} / 1.1$ & $\mathrm{D} / 1.8$ & 108/None & $\begin{array}{l}\text { Pupils } \\
\text { Dilated* }\end{array}$ & $\begin{array}{l}2 \text { minutes } \\
20 \mathrm{sec} /-4\end{array}$ & 1.4 \\
\hline 4 & $8 \mathrm{~m}$ & $\mathrm{~F}$ & $\begin{array}{l}\text { Cataract/15mins/ } \\
1 / 1 \text { st }\end{array}$ & sevo & $\mathrm{Y} / 1$ & $\mathrm{D} / 1.5$ & 110/None & $\begin{array}{l}\text { Pupils } \\
\text { dilated* }\end{array}$ & 1minute-3 & 1.2 \\
\hline 5 & 1 & $\mathrm{~F}$ & $\begin{array}{l}\text { capsulotomy/ } \\
15 \text { minutes/2/2nd }\end{array}$ & sevo & $\mathrm{Y} / 0.9$ & $\mathrm{D} / 1.4$ & 120/None & $\begin{array}{l}\text { Pupils } \\
\text { dilated* }\end{array}$ & $\begin{array}{l}1 \min 45 \\
\mathrm{sec} /-3\end{array}$ & 1.3 \\
\hline 6 & 1.1 & $\mathrm{~F}$ & $\begin{array}{l}\text { Botox**/ } \\
\text { 10minutes /1/1st }\end{array}$ & sevo & No & $\mathrm{B} / 2$ & 120/None & $2 \mathrm{~mm} /$ none & 2 mins/-2 & 1.2 \\
\hline 7 & $9 \mathrm{~m}$ & $\mathrm{M}$ & $\begin{array}{l}\text { Cataract surgery/ } \\
15 \text { minutes/2/1st }\end{array}$ & sevo & $\mathrm{Y} / 1$ & $\mathrm{~B} / 1.8$ & 130/None & $\begin{array}{l}\text { Pupil } \\
\text { dilated* }\end{array}$ & $\begin{array}{l}\text { 1minute } 30 \\
\text { seconds/-3 }\end{array}$ & 1.4 \\
\hline 8 & $10 \mathrm{~m}$ & $\mathrm{M}$ & $\begin{array}{l}\text { Botox**/ } \\
\text { 10minutes/1/1st }\end{array}$ & sevo & No & $\mathrm{B} / 1.4$ & 146/None & $1.4 \mathrm{~mm} /$ none & 1 minute/-2 & 1.2 \\
\hline
\end{tabular}


Yrs=years; $\mathrm{m}=$ months; $\mathrm{M}=$ male; $\mathrm{F}=$ female; $\mathrm{Sx}=$ surgery; sevo=sevoflurane; $\mathrm{Y}=\mathrm{yes} ; \mathrm{N}=\mathrm{no} ; \mathrm{MAC}=$ minimal alveolar concentraton; $\mathrm{BIS}$-bispectral index; $\mathrm{B}=$ before start of surgery; $\mathrm{D}=$ during surgery or after start of surgery; $\mathrm{HR}=$ heart rate; $\mathrm{OCR}=$ oculo-cardiac reflex;

*Pupils were pharmacologically dilated

**Botox injection was given in medial rectus in case of infantile esotropia under direct inspection with small conjunctival injection after hooking muscle

\section{Figures}

\section{Figure 1}

Photograph of the left eye of case 1 (congenital cataract) showing both up and down drift with scores for various eye positions. Eye seen in up-drifted position $(+4)$ before the start of surgery $(M A C=1)$, following which sevoflurane concentration was increased and eye slowly drifted down (+4 to +1) (A-D), got centralized momentarily (E) but overshoot or drifted in downgaze (F-I) and eye assumed an eccentric position in downgaze $(-1$ to -4$)$ at MAC $=1.8$.

MAC- minimum alveolar concentration

\section{Figure 2}

Photograph of eyes of patients who showed downdrift alone without updrift. (A, B) Both eyes of case 7 (before botox injection) showed (A) symmetric down-positioning of eyes before the start of surgery (MAC 1.4) when eyes were cleaned, draped, and opened following which (B) sevoflurane concentration was decreased and eyes returned to the central position (MAC=1.2) within a minute of decreasing sevoflurane concentration. It should be noted that recorded values of MAC at the time of intubation were 1.7 and MAC was stabilized to 1.4 within a few minutes of decreasing sevoflurane concentration after intubation when eyes were opened to see their position at the time of cleaning and draping.

(C, D) The right eye of same patient 7 (before second botulinum injection) at 14 months of age in the central position (MAC=1) at the time of the start of surgery (C) but as anesthesia was deepened (to improve oxygen saturation as patient was not able to maintain on spontaneous breathing), eye turned in and down (D) after temporary release of muscle traction during surgery following passage of traction suture, conjunctival incision and hooking of muscle. (at MAC=1.4)

(E.F) Photographs of eccentric eye positioning in downgaze with slight adduction (towards the nose) in left eye before start of surgery in case 9 (infantile esotropia) ( $M A C=1.6, B I S=34)(E)$ and after eye achieved centralized position when the depth of anesthesia was decreased (MAC 1.3, BIS 50).

MAC- minimum alveolar concentration; BIS-bispecrtral index 


\section{Figure 3}

Pre-operative photograph of both eyes showing asymmetric down-positioning of eyes in case 10 (infantile esotropia) (A) Right eye more down-positioned than left eye at $M A C=2$. (B) Pre-operative clinical profile of same patient showing esotropia with left eye Dissociated vertical deviation.

MAC- minimum alveolar concentration

\section{Supplementary Files}

This is a list of supplementary files associated with this preprint. Click to download.

- video1.wmv

- video2.mp4

- video3.mp4

- eFigure4.png 